\title{
Rearrangements of Ammonium Nitrate Cluster Ions with High Internal Energy
}

\author{
R.J. Doyle and B.I. Dunlap \\ Chemistry Division, Naval Research Laboratory, Washington, DC 20375, U.S.A.
}

\begin{abstract}
Sputtering of condensed-phase ammonium nitrate yields an extensive distribution of negative cluster ions of the form $\left[\left(\mathrm{NH}_{4} \mathrm{NO}_{3}\right)_{n} \mathrm{NO}_{3}\right]^{-}, n \geq 3$. Collision-induced dissociation of mass-selected cluster ions suggests that the first two members of the series, $n=1$ and $n=2$, are missing because the ions rearrange to lose one or more ammonia molecules. Gradient-corrected density-functional calculations show that $\mathrm{NH}_{4} \mathrm{NO}_{3}$ is strongly hydrogen bonded and that $\left[\left(\mathrm{NH}_{4} \mathrm{NO}_{3}\right) \mathrm{NO}_{3}\right]^{-}$has no hydrogen bonds, consistent with this ion rearranging to lose $\mathrm{NH}_{3}$ to form the strongly hydrogen-bonded ion $\left[\mathrm{H}\left(\mathrm{NO}_{3}\right)_{2}\right]^{-}$.
\end{abstract}

\section{INTRODUCTION}

As its name implies, ammonium nitrate (AN) can be viewed as an ionic solid made up of ammonium cations and nitrate anions. If this were a complete description of the solid, then sputtering would be expected to yield all ions of the form $\left[\left(\mathrm{NH}_{4} \mathrm{NO}_{3}\right)_{n} \mathrm{NH}_{4}\right]^{+}$as the only singly-charged ions in the positive-ion spectrum and all jons of the form $\left[\left(\mathrm{NH}_{4} \mathrm{NO}_{3}\right) \mathrm{NO}_{3}\right]^{-}$as the only singly-charged ions in the negative-ion spectrum. Such a positive-ion mass spectrum, for $n$ from 1 to 43 , is indeed seen upon sputtering $A N[1,2]$. The sputtered negative-ion spectrum is not as expected based on this ionic model, however. Instead, only [( $\left.\left.\mathrm{NH}_{4} \mathrm{NO}_{3}\right) \mathrm{NO}_{3}\right]^{-}, n \geq 3$, negative ions are seen [3]. Two negative cluster ions ( $n=1$ and 2 ) are observed in trace amounts only. The absence of the $n=1$ ion is all the more surprising because all the larger clusters would be expected to have this ion as their core.

The key to understanding why the first two members of the negative ion series are missing requires considering the effect of hydrogen-bonding on the structure of AN. If a proton were transferred from the ammonium cation to the nitrate anion in a formula unit, then the formula unit could be viewed as an ammonia molecule complexing through its lone-pair orbital to nitric acid. The resonance between the ionic and molecular interactions is hydrogen bonding, and the strength of the hydrogen bond is correlated with how far a proton is separated from each ammonium cation.

In either the positive or negative AN clusters, one or more of the ammonia-nitric acid bonds can cleave. An overall charge-dependent imbalance between ammonia or nitric acid fragments that escape during the formation of ions in the sputtering process rationally gives rise to the other relatively abundant cluster ions in the positive and negative mass spectra. The delicate balance between ionic and molecular bonding explains the absence of the $n=1$ and 2 ions in the sputtered negative ion spectrum. 


\section{EXPERIMENT}

In this work, the AN mass spectra were obtained using a ZAB-2F (VG Analytical Ltd.) reversegeometry, double-focusing mass spectrometer operated with an accelerating potential of $8 \mathrm{kV}$. Samples were prepared by pressing ammonium nitrate into indium foil affixed to the tip of a fast-atom bombardment probe. Xenon atoms with an average kinetic energy of $6.5 \mathrm{keV}$ were generated using a saddle-field gun operating at $8 \mathrm{kV}$ with an ion current of $1.5 \mathrm{~mA}$. The xenon neutral current equivalent was approximately $7 \mu \mathrm{A}$ applied to a target area of $4 \mathrm{~mm}^{2}$.

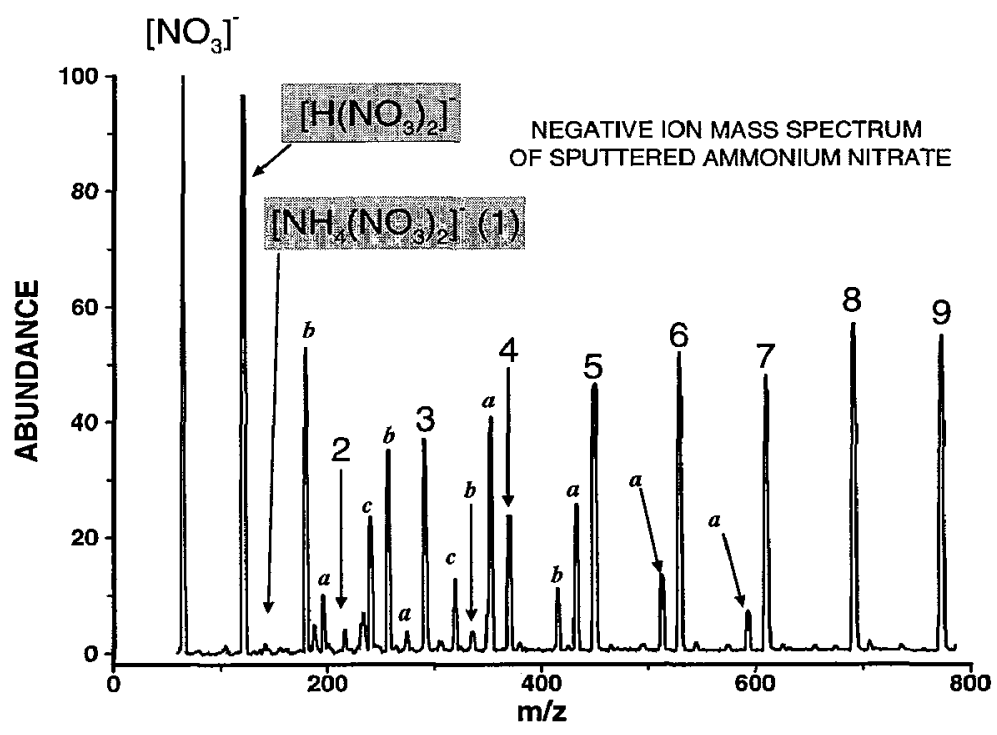

Figure 1. Partial negative-ion mass spectrum of sputtered ammonium nitrate.

Figure 1 shows the negative-ion mass spectrum of sputtered ammonium nitrate. Clusters with the general formula [ $\left.\left(\mathrm{NH}_{4} \mathrm{NO}_{3}\right)_{n} \mathrm{NO}_{3}\right]^{-}$are indicated by the numbers 1-9. Cluster ions with $n=$ $3-40$ are observed in relatively high abundance; the $n=1$ ion is almost lost in the noise, and the $n=2$ ion is far less abundant than the more massive members of the series. For smaller cluster sizes, the abundance of species apparently formed by losses of single and multiple $\mathrm{NH}_{3}$ from $\left[\left(\mathrm{NH}_{4} \mathrm{NO}_{3}\right)_{n} \mathrm{NO}_{3}\right]^{-}$ions becomes pronounced. These are designated a, b, and c, corresponding to losses of 1, 2, and 3 ammonia molecules, respectively. Loss of $\mathrm{NH}_{3}$ from $\left[\mathrm{NH}_{4}\left(\mathrm{NO}_{3}\right)_{2}\right]^{-}$(the $n=1$

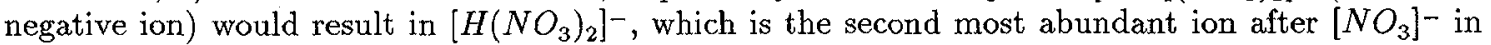
the spectrum.

To further test our hypothesis that the lack of the $n=1$ and 2 negative ions results from these species rearranging and fragmenting, collision-induced-dissociation (CID) experiments were performed. The negative ions that are fairly abundant in the sputtered spectrum can be massselected by the magnetic sector of the instrument. These mass-selected species are then collided with a collision gas (helium in these experiments) in a field-free region of the instrument and the resultant fragment ions detected and identified[4,5]. The $n=1$ cluster is found in very low abundance in the CID spectra of all AN clusters examined $(n=3-15)$. Figure 2 shows the negative-ion CID spectrum of $\left[\left(\mathrm{NH}_{4} \mathrm{NO}_{3}\right)_{7} \mathrm{NO}_{3}\right]^{-}$. As in Figure 1, the numbers indicate $\left[\left(\mathrm{NH}_{4} \mathrm{NO}_{3}\right)_{n} \mathrm{NO}_{3}\right]^{-}$ions, and subsequent fragmentation of these ions leads to ions designated $a, b$, and $c$, which correspond to losses of 1,2 and 3, ammonia molecules, respectively. The relative abundances of ions in the CID spectra are similar to those seen in the directly sputtered mass spectrum. For all parent 


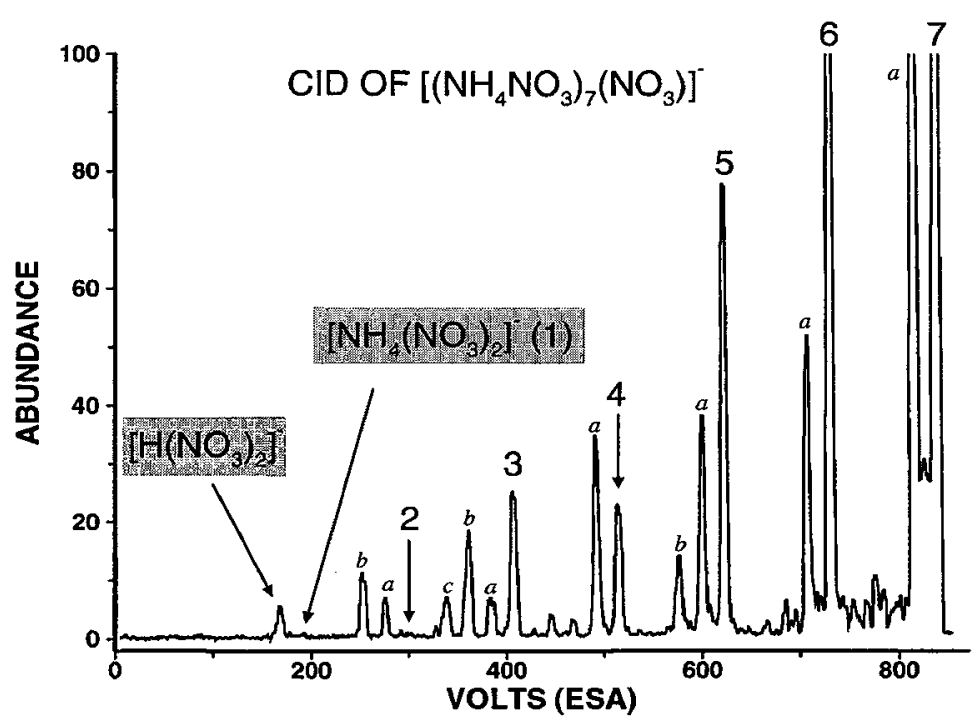

Figure 2. CID spectrum of $\left[\left(\mathrm{NH}_{4}\right)_{7} \mathrm{NO}_{3}\right]^{-}$.

cluster ions examined, $\left[\mathrm{NH}_{4}\left(\mathrm{NO}_{3}\right)_{2}\right]^{-}$was observed in very low abundance. The spectra suggest that $\left[\mathrm{NH}_{4}\left(\mathrm{NO}_{3}\right)_{2}\right]^{-}$dissociates rapidly to form $\left[\mathrm{H}\left(\mathrm{NO}_{3}\right)_{2}\right]^{-}$by loss of $\mathrm{NH}_{3}$.

Both the positive-ion and the negative-ion mass spectra of sputtered ammonium nitrate are more complicated than a simple ionic model would suggest. Previous work on positively charged ammonium nitrate clusters, under the same experimental conditions, identified the cluster-ion series, $\left[\left(\mathrm{NH}_{4} \mathrm{NO}_{3}\right)_{n} \mathrm{NH}_{4}\right]^{+}$, where $n=1$ to $>43$ inclusive[3]. This is as expected from a simple ionic model. On the other hand, studies of the positive ions show that these ions can also rearrange and dissociate by the loss of a single $\mathrm{HNO}_{3}$ molecule. As discussed above, the negative-ion clusters dissociate by losses of one to three $\mathrm{NH}_{3}$ molecules and the $n=1$ and 2 species are missing from the corresponding negative-ion series.

These experimental results are insufficient to answer the question of why the $n=1$ species is not observed in the negative-ion spectra, while the corresponding $n=1$ species is always abundant in the positive-ion spectra. The lack of thermodynamic data for many of these species suggests a purely theoretical approach to the question.

\section{THEORY}

Density-functional theory [7] is an appropriate method to use to study AN clusters where both ionic and hydrogen bonding compete in determining structures and energetics. Gradient-corrected functionals are very important because of the hydrogen bonding and the fact that relative total energies are important [8]. The deMon $[9,10]$ computer code was employed, which uses three different Gaussian basis sets [11]: one to fit the one-electron orbitals, one to fit the exchange-correlation part of the electronic potential, and one to variationally fit [12] the density to obtain the Coulomb part of the electronic potential. The default double-zeta plus polarization-on-heavy-atoms basis set was used with the Becke exchange [13] and Perdew correlation [14] potentials. The geometries of selected clusters were optimized, and their total energies were evaluated are listed in Table 1.

Studying the optimized equilibrium structures of these molecules and ions is a good way to understand the energetics. Figure 3 shows the optimized structure of the ammonium nitrate molecule, 
TABLE 1. The Becke-Perdew density-functional total molecular energies in Hartree atomic units.

\begin{tabular}{cccccc}
\hline Molecule & Energy & Positive Ion & Energy & Negative Ion & Energy \\
\hline $\mathrm{NH}_{3}$ & -56.5703 & {$\left[\mathrm{NH}_{4}\right]^{+}$} & -56.9104 & {$\left[\mathrm{NO}_{3}\right]^{-}$} & -280.4672 \\
$\mathrm{HNO}_{3}$ & -280.9928 & {$\left[\left(\mathrm{NH}_{4}\right)_{2} \mathrm{NO}_{3}\right]^{+}$} & -394.5503 & {$\left[{\left.\mathrm{H}\left(\mathrm{NO}_{3}\right)_{2}\right]^{-}}_{-}^{-561.5085}\right.$} \\
$\mathrm{NH}_{4} \mathrm{NO}_{3}$ & -337.5876 & & & {$\left[\mathrm{NH}_{4}\left(\mathrm{NO}_{3}\right)_{2}\right]^{-}$} & -618.1067 \\
\hline
\end{tabular}

$\left[\mathrm{NH}_{4} \mathrm{NO}_{3}\right]$. In the upper part of the figure, the molecule is depicted in space-filling form. In the lower part of the figure the bond distances and bond angles are given. The atoms, from darkest to lightest are nitrogen, oxygen, and hydrogen. The fourth hydrogen atom of the $\mathrm{NH}_{4}$ group is pulled away by $0.6 \AA$ by the $N O_{3}$ group. This structure agrees very well with that obtained at the Hartree-Fock level of theory using a 4-31G Gaussian basis set [15]. Viewed as a molecule formed from ammonia and nitric acid components, the gradient-corrected density-functional bonding energy of AN is $15.4 \mathrm{kcal} / \mathrm{mol}$. This binding energy is somewhat less than $21.7 \mathrm{kcal} / \mathrm{mol}$ obtained in the Hartree-Fock calculation, but the density-functional calculations also support the conclusion that AN contains one of the strongest known hydrogen bonds [15]. Viewed as a molecule formed from an ammonium cation and a nitrate anion its binding energy would be $132 \mathrm{kcal} / \mathrm{mol}$.

\section{$\mathrm{NH}_{4} \mathbf{N O}_{3}$}

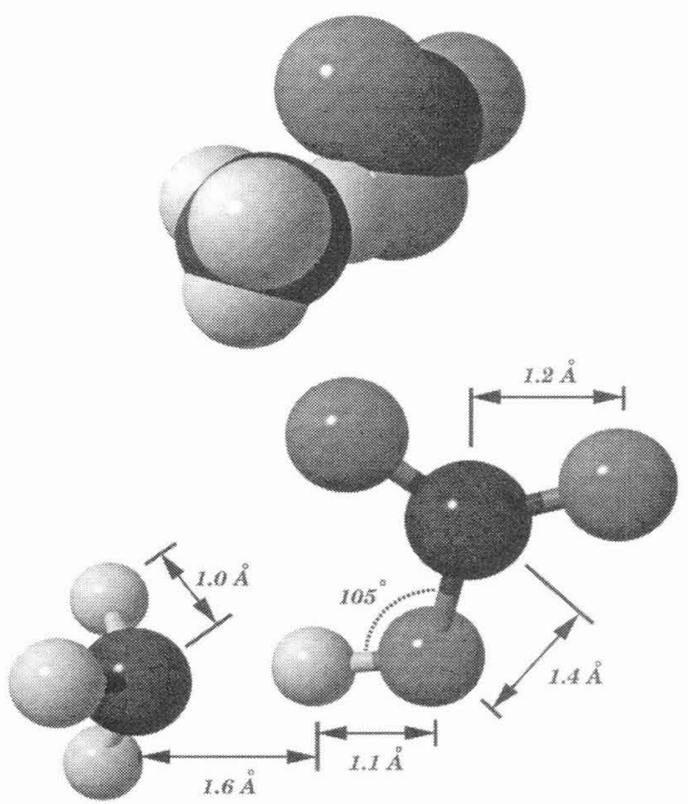

Figure 3. Structure of $\left[\mathrm{NH}_{4} \mathrm{NO}_{3}\right]$.

\section{$\mathrm{NO}_{3}\left(\mathrm{NH}_{4}\right) \mathrm{NO}_{3}^{-}$}

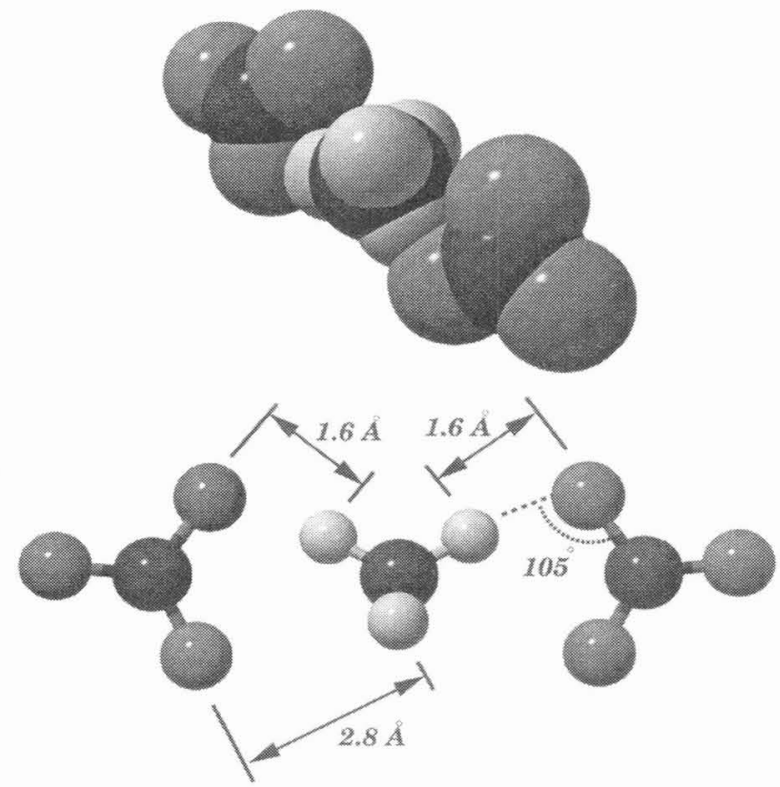

Figure 4. Structure of $\left[\mathrm{NH}_{4}\left(\mathrm{NO}_{3}\right)_{2}\right]^{-}$.

Figure 4 gives space-filling and ball-and-stick depictions of the geometry of $\left[\mathrm{NH}_{4}\left(\mathrm{NO}_{3}\right)_{2}\right]^{-}$. The $1.6 \AA$ distance between oxygen and hydrogen atoms shows that there is essentially no hydrogen bonding in this ion. Viewed as being formed from AN and $\left[\mathrm{NO}_{3}\right]^{-}$, its density-functional binding energy is only $32.6 \mathrm{kcal} / \mathrm{mol}[3]$.

Figure 5 gives space-filling and ball-and-stick depictions of the geometry of $\left[\left(\mathrm{NH}_{4}\right)_{2} \mathrm{NO}_{3}\right]^{+}$. The $1.5 \AA$ distance between the oxygen and hydrogen atoms shows that there are two weak hydrogen bonds. These bonds are slightly stronger than in the corresponding negative ion of Figure 4. Viewed 


\section{$\mathrm{NH}_{4}\left(\mathrm{NO}_{3}\right) \mathrm{NH}_{4}^{+}$}

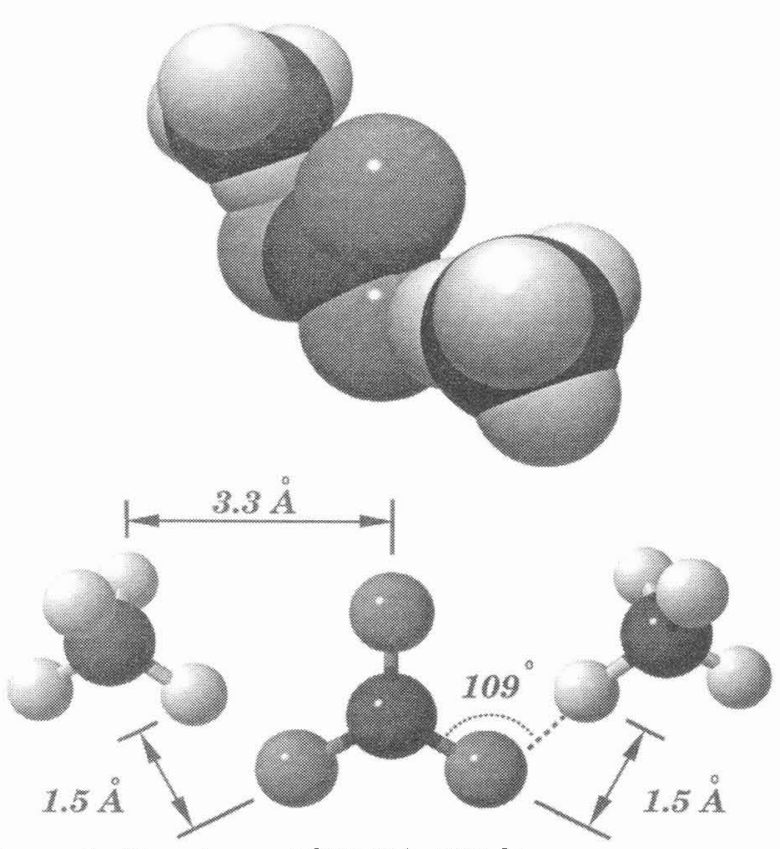

Figure 5. Structure of $\left[\left(\mathrm{NH}_{4}\right)_{2} \mathrm{NO}_{3}\right]^{+}$.

\section{$\mathrm{NO}_{3}(\mathrm{H}) \mathrm{NO}_{3}^{-}$}
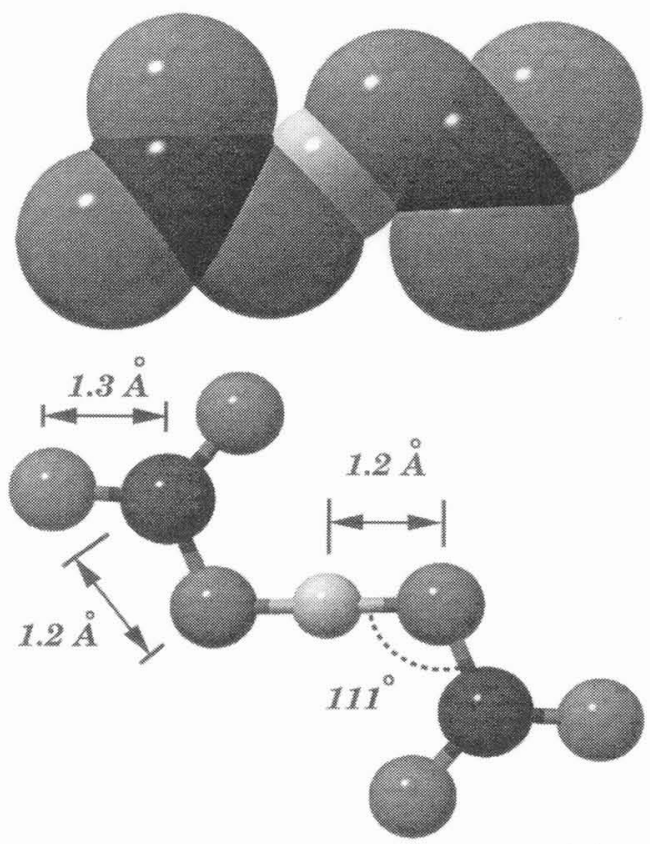

Figure 6. Structure of $\left[\mathrm{H}\left(\mathrm{NO}_{3}\right)_{2}\right]^{-}$.

as being formed from $\mathrm{AN}$ and $\left[\mathrm{NH}_{4}\right]^{+}$, the $\left[\left(\mathrm{NH}_{4}\right)_{2} \mathrm{NO}_{3}\right]^{+}$density-functional binding energy is 32.8 $\mathrm{kcal} / \mathrm{mol}$, somewhat larger than the binding energy of the corresponding negative ion.

The main difference between the positive and negative $n=1$ ions is the level of hydrogen bonding that remains after rearrangement if the AN molecule of either ion is fragmented. $\left[\mathrm{NH}_{4} \mathrm{NH}_{3}\right]^{+}$, formed by the loss of $\mathrm{HNO}_{3}$ from $\left[\left(\mathrm{NH}_{4}\right)_{2} \mathrm{NO}_{3}\right]^{+}$, has less hydrogen bonding than $\left[\mathrm{H}\left(\mathrm{NO}_{3}\right)_{2}\right]^{-}$, formed by the loss of $\mathrm{NH}_{3}$ from $\left[\mathrm{NH}_{4}\left(\mathrm{NO}_{3}\right)_{2}\right]^{-}$. The later ion is depicted in Figure 6 . The $\mathrm{O}-\mathrm{H}$ bond distances of $1.2 \AA$ are in agreement with an analysis of X-ray diffraction data [16]. Viewed as being formed from nitric acid and $\left[\mathrm{NO}_{3}\right]^{-}$, its density-functional binding energy is $30.4 \mathrm{kcal} / \mathrm{mol}$.

The density-functional energetics of the $n=1$ negative ion rearrangement and fragmentation are shown in Figure 7. If $\left[\mathrm{NH}_{4}\left(\mathrm{NO}_{3}\right)_{2}\right]^{-}$is created with a small amount of internal energy, as little as $18 \mathrm{kcal} / \mathrm{mol}$, if there is no reverse activation energy, then it should be possible for it to rearrange to lose ammonia and form the very stable hydrogen dinitrate ion that is the second most abundant ion in the sputtered mass spectra of AN (Figure 1).

\section{CONCLUSIONS}

The absence, or low abundance, of $\left[\left(\mathrm{NH}_{4} \mathrm{NO}_{3}\right) \mathrm{NO}_{3}\right]^{-}(\mathrm{n}=1)$ is a consequence of the fact that this ion has essentially no hydrogen bond stabilization and that the ion is created with significant internal energy by the sputtering process. Two dissociation pathways are accessible, loss of $\mathrm{NH}_{3}$ and loss of $\mathrm{NO}_{3}^{-}$, which are only $18 \mathrm{kcal} / \mathrm{mol}$ and $33 \mathrm{kcal} / \mathrm{mol}$, respectively, above the ground state of the $\mathrm{n}=1$ ion. Both exit channels lead to products with strong hydrogen bonds. More ammonium nitrate molecules surrounding the $\mathrm{n}=1$ ion increase the solvation energy to stabilize the larger clusters. 


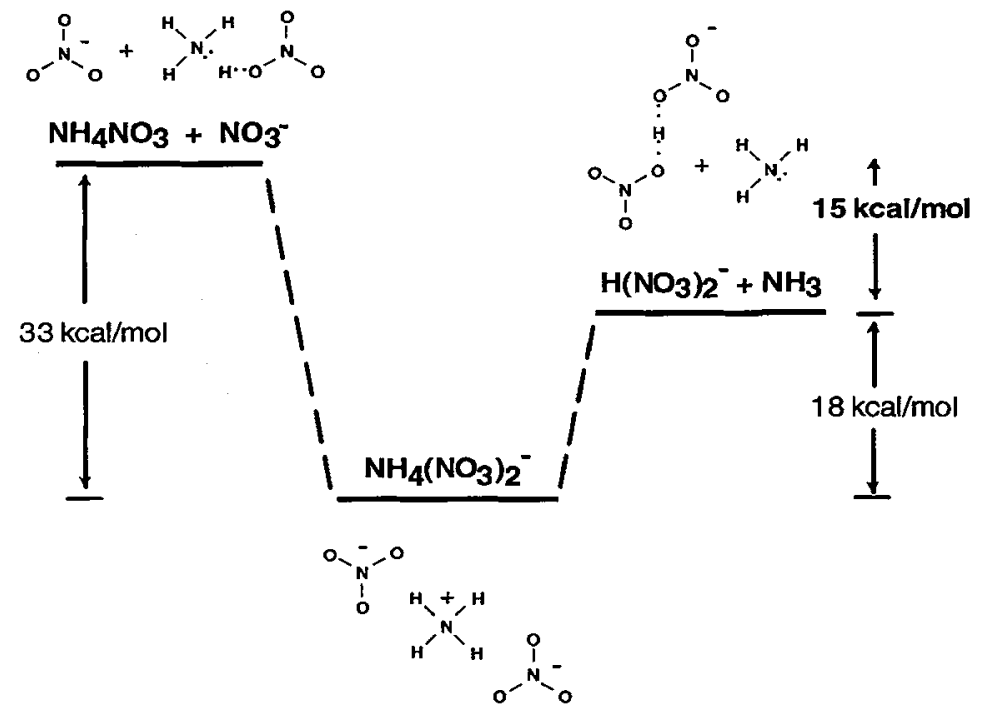

Figure 7. Density-functional energetics of $\left.\left[\mathrm{NO}_{3}\right)_{2} \mathrm{NH}_{4}\right]^{-}$association and dissociation pathways.

\section{Acknowledgement}

BID thanks Dennis Salahub for inclusion in the deMon collaboration. This work was supported by the Propulsion and Energetic Materials Program of the Mechanics Division of the Office of Naval Research, the Physics Division (Contract \#N0001494WX23009) of the Office of Naval Research, and the Naval Research Laboratory Energetic Materials Accelerated Research Initiative.

\section{References}

[1] Doyle R.J., Jr., J. Am. Chem. Soc. 115 (1993) 5300-5301.

[2] Doyle R.J., Jr., J. Am. Chem. Soc. 116 (1994) 3005-3011.

[3] Doyle R.J., Jr., and Dunlap B.I., J. Phys. Chem. 98 (1994) 8261-8263.

[4] Doyle R.J., Jr., J. Am. Chem. Soc. 110 (1988) 8261-8263.

[5] Doyle R.J., Jr., J. Org. Mass Spectrom. 28 (1993) 83-91.

[6] Parr R.G., Yang W., Density Functional Theory of Atoms and Molecules (Oxford Univ. Press, Oxford, 1989).

[7] Andzelm J.; Wimmer E., J. Chem. Phys. 96 , (1992), 1280-1303.

[8] Salahub D.R., Fournier R., Młynarski P., Papai I., St.-Amant A., Ushio J., "Gaussian-based Density Functional Methodology, Software, and Applications", Density Functional Methods in Chemistry, Columbus 7-9 May 1990, J. Labanowski and J. Andzelm Eds. ( Springer, New York, 1991) pp. 77-100.

[9] St-Amant A., Salahub D.R., Chem. Phys. Lett. 169 (1990) 387-392.

[10] Sambe H., Felton R.H., J. Chem. Phys. 62 (1975) 1122-1126.

[11] Dunlap B.I., Connolly J.W.D., and Sabin J.R., J. Chem. Phys. 71, 3396-3402; 4993-4999 (1979).

[12] Becke A.D., Phys. Rev. A 38 (1988) 3098-3100.

[13] Perdew, J.P., Phys. Rev. B 33 (1986) 8822-8824.

[14] Latajka Z., Szczesśniak M.M., Ratajczak H., Orville-Thomas W.J., J. Comp. Chem. 1 (1980) 417-419.

[15] Barlič B., Hadži D., Orel B., Spectrochim. Acta 37 A (1981) 1047-1048. 


\section{4-2 Discussion}

Questions - Answers, Comments

\section{Rullière - Gupta :}

$\mathbf{Q}$ : You observed disappearance of the $\mathrm{C}-\mathrm{N}$ vibration mode but not for the other modes $\left(\mathrm{CH}_{3}\right.$, etc). You interpreted $\mathrm{CN}$ mode disappearing as the image of the nitromethane breaking. But in this case, $\mathrm{CH}_{3} \cdot$ and $\mathrm{NO}_{2}$. fragments are formed with different vibration mode not related to $\mathrm{CH}_{3} \mathrm{NO}_{2}$ modes. As a consequence nitromethane modes should disappear, not only $\mathrm{CN}$ mode. How do you explain this intriguing fact?

A : You have asked an excellent question, and at the moment, I do not have an answer. It is a very important issue and one that we are thinking about. Because our results are very recent, we have not analyzed or understood them completely. Any suggestion you may have are welcome and will be acknowledged appropriately.

$\mathbf{Q}$ : Sensitization by small amount of amine is very interesting but opens some questions.

1) is this sensitization process related to electron donor ability of amines and what is the mechanism?

2) how to explain that such a small amount can perturb all the sample taking into account this small concentration?

A : Regarding the first part of your question, the mechanism for sensitization has not been resolved. Cook and Haskin have proposed a mechanism based on hydrogen bonding (see the latest International Detonation Symposium). In contrast, Constantinon and Chandhri have proposed a mechanism based on the formation of a charge transfer complex. I am hoping, we can clarify this issue in the future.

Regarding the second part of your question, I believe that the small amount of amine initiates the reaction and very quickly there is an auto-catalytic reaction (as suggested by Constantinon) takes over. Once the reaction is initiated, the subsequent reactions may be very complicated.

\section{Boileau - Gupta :}

$\mathbf{Q}:$ a comment - Suggestion

Using a tertiary amine instead of the DETA or EDA, are the shifts the same ?

Is it possible to add before shock a product that picks up a $\mathrm{CH}_{3}$. or adds to $\mathrm{C}=\mathrm{N}$ ?

$\mathbf{Q}$ : To study ethylnitrate (usable and not very dangerous liquid) under shock, (is it a shift of Raman lines ?) without and with some traces of amine (verification by Presles if amine is a sensitizer, I think no but it is to be verified) and after, put in ethylnitrate some nitromethane, without and with amine to see if the shifts in the nitromethane bands are modified. Is it possible by this way, to see if there are clusters in nitromethane?

A : I think that these suggestions are interesting and address a question. Shock-business is a hard business and we have to work in a well defined direction and choose and concentrate on well defined sample with precise experimental conditions. 


\section{Melius - Gupta :}

$\mathrm{Q}$ : The disappearance of the $\mathrm{C}-\mathrm{N}$ bond frequency does not necessarily mean that the $\mathrm{C}-\mathrm{N}$ bond is breaking. It is possible that a" $\mathrm{C}=\mathrm{N}$ - bond or a $-\mathrm{C} \equiv \mathrm{N}$ is being formed, such as in $\mathrm{HCNO}, \mathrm{HNCO}$ or $\mathrm{HCN}$. Is it possible for you to look for such new bond formations?

A : In principle, the answer is yes. In practice, it will depend on the concentration. As you are aware, Raman scattering is a weak process.

\section{Mialocq - Gupta :}

$\mathbf{Q}$ : What is the physical origin of the shift of the nitromethane UV absorption spectrum under the pressure increase? Is it some increase of the molar extinction coefficient or a real shift due to some Onsager cavity type effect?

A : Because our interest was in the large shift due to chemical reactions, we have not thought in detail about the pressure induced shift. However, this latter issue has been addressed in our work on CS 2 (J.Chem.Phys. 95, 451 (1991) ; J.Phys.Chem. 94, 2857 (1990))

\section{Dremin - Gupta}

Q:I am afraid about the influence of the interface between the sample and the target. I mean heat conductivity, roughness of the surface, etc. Can you comment the reproductibility of the results?

A : We know very well this problem and took great care about the experimental conditions. For example we subject sample to many laser shots to check that, we used stainless materials to avoid contaminations. Concerning nitromethane we used only fresh materials to avoid contaminations with metal and also sapphire windows. We checked eveything was possible to check.

\section{Nelson - Delpuech}

$\mathbf{Q}$ : May have some precision about the excitation mechanism that you suggested ? Is it a photon-polariton or a phonon-polariton, or an I.R. photon-polariton?

A : The mechanism is a coupling between phonon and photon and it is a phonon-polariton.

\section{Melius - Dufort}

$\mathbf{Q}$ : Concerning the possible role of electronic excited states I have two remarks. The first one is concerned with time scale. If necessary time to break a bond is several hundred nanoseconds, excited state is not necessary, but if it is $100 \mathrm{ps}$ it is necessary and I can consider excited state as a necessary mean. The second point is that you showed photon correlation with repulsive curve. A repulsive curve leads to radiationless process not involving photons. Can you comment?

A : I presented a correlation between excited state characteristics and shock-sensitivity. The excited state was dissociative, but these correlations are not concerned with the photons emitted by the laser. 
Gupta - Dufort

$\mathbf{Q}$ : You showed quantum mechanical calculations using harmonic oscillator solution, you put a shock-wave and calculating the population density. Can you give details about these correlations? A : Yes, it is a pure analytic calculation using Hermitte polynomes for eigen functions of the harmonic oscillator. That shows the evolution of the excitation probability as a function of the speed of the detonation velocity. The shock is simulated by a Heavy-side perturbation function.

\section{Mialocq - Kondrikov :}

$\mathbf{Q}$ : Do you have any spectroscopic evidence for the existence of a complex between sulfuric acid and nitromethane (or TNT) since you explain the strong sensibilizing effect of inorganic acids on the nitrocompounds detonation by the formation of a nitromethonium sulfate?

A : Very good question and very short answer : no.

\section{Odiot - Kondrikov}

Comment : Calculations show that when $1 \mathrm{me}$ is added to the $\mathrm{C}$ and $\mathrm{N}$ atoms of the $\mathrm{C}-\mathrm{N}$ bond, the strength of the bond increases by $1 \mathrm{kcal} / \mathrm{mole}$. It decreases in the opposite case. If you have nitromethane in a bath of $\mathrm{H}_{2} \mathrm{SO}_{4}$, it is surrounded by many protons, and the electronic charge on $\mathrm{C}$ and $\mathrm{N}$ will decrease, thus the bond strength decreases strongly. You have to take account of this effect when you study the sensitivity of nitromethane in a bath of protons.

Melius : There are two separate effects which are occuring. One is the environment of charge species which can help weaken bonds as you mention. The other thing that happens is say a proton charge can go on to the molecule and make a new molecule which now makes extremely different chemistry. Thus we must consider both effects.

\section{Mialocq - Dlott :}

$\mathbf{Q}$ : In your picosecond time scale transfer measurements in nitromethane, you made use of dye heaters absorbing at $1 \mu \mathrm{m}$. What is the energy transfer mechanism involved, considering the very short lifetime of IR absorbing dyes (probably polymethinecyanine dyes) ? What are the characteristic time constants? Do you take into account the polar solvent relaxation around the dye solute and the vibrational cooling which both occur below 10 picoseconds according to the current litterature findings?

A : The dye heater we use is called IR-165. We have studied it in detail (J.Phys.Chem., 1992). The vibrational cooling time is about 4 ps. That is sufficiently faster than our laser pulses that its vibrational cooling and other photophysical processes do not play a significant role in our multiphonon up-pumping measurements.

$\mathbf{Q}$ : Electronic relaxation is $1 \mathrm{ps}$ but vibrational relaxation in ground state is $4 \mathrm{ps}$ for dyes. What do you observed in nitromethane?

A : For nitromethane we used time-resolved incoherent Anti-Stokes Raman Scattering technics. We observed that the build-up of energy was on a two hundred picosecond time-scale. Since the 
energy of the dye is not immediately transferred to nitromethane vibration, we imagine that there is collisional degree of freedom that we called "phonons" and explain this delay.

\section{Rullière - Dlott :}

$\mathbf{Q}:$ For energy transfer processes you showed two kinetics curves have the same rise-time but delayed in respect to each other. What is the mechanism explaining this delay while the rise-times look similar?

A : The details of vibrational energy transfer mechanisms are complicated. They have been discussed by Hill and Dlott (J.Chem.Phys.) in 1988 and also in a recent J.Phys.Chem. article on nitromethane by Chen, Tolbert and Dlott. In the regime under study, a higher energy vibration h $\Omega$ transfers energy only to lower energy vibrations whose energies are within $\mathrm{h} \Omega_{\max }$, where $\Omega_{\max }$ is the phonon cut-off frequency. The delay time is the time required to make a few steps in energy. For a few steps, the rise time is not increased so much.

Dremin to Workshop : Once again I'd like to turn our discussion to the problem we were going to discuss, namely to the problem of shock mechanical energy transfer to EM's molecules. At present some ideas on the problem have been already developed ; Gilman's idea of electronic excitation through metallization, our idea of electronic excitation, dissociation and nonequilibrium decomposition of EM's molecules in the detonation shock wave front, and others. My proposal is to spend more time to discuss on (to my opinion) the most important problem for the present for the further progress of the detonation physical model - the problem of shock mechanical energy transfer to EM's molecules.

\section{Kondrikov - Volk :}

$Q$ : How big was the containment you filled with Argon?

A : $1.5 \mathrm{~m}^{3}$.

Kondrikov : So you had about $1.5 \mathrm{Kg}$ of $\mathrm{Ar}$ and $0.33 \mathrm{Kg}$ of explosive. Then cooling of the mixture by big volume of Ar stopped the reaction at relatively high temperature and pressure and lets you to preserve carbon in products. 


\title{
IV THEORETICAL ASPECTS OF NON-LINEAR DYNAMICS OF DETONATION
}

\author{
Chairman : Marcel Barrère, Haut Conseiller de l'ONERA
}

Je remercie Madame Odiot pour son aimable invitation à présider cette Session. Je pense que, dans le domaine complexe de la détonation, de larges discussions sont nécessaires pour affirmer et affiner nos points de vue. Je voudrais souligner trois points qui me paraissent essentiels concernant:

- le sujet fondamental de l'Atelier "Approches microscopique et macroscopique des détonations",

- le rôle de la thermodynamique dans l'étude des détonations,

- l'importance du temps dans l'analyse de ces phénomènes.

L'ensemble de ces trois points se situe dans le développement moderne de la mécanique non-linéaire.

a) La compréhension de la coexistence d'une onde de choc et d'une onde de combustion n'est possible que si l'on dispose d'une analyse fine locale performante, a la fois dans l'espace $\left(10^{-6} \mathrm{~mm}\right)$ et dans le temps $\left(10^{-14} \mathrm{~s}\right)$, c'est l'approche microscopique, et si l'on dispose de l'analyse des répercussions globales, c'est l'approche macroscopique. Ces deux manieres sont nécessaires et sont d'un même poids. Elles ne peuvent être dissociées car elles sont complémentaires et s'enrichissent mutuellement.

C'est la démarche d'Hadamard et Duhem, Poincaré insiste sur l'importance du passage du local au global, en particulier en topologie (Analysis situs).

b) Le deuxième point souligne, en particulier dans l'analyse de la détonation, l'importance de la thermodynamique. Dans le passé, ce rôle a été primordial pour la détermination de la vitesse de détonation, importance de la production d'entropie, qui est minimale en aval de l'onde. Nous pensons que ce rôle n'est pas terminé, notamment dans la partie irreversible à laquelle est consacrée une théorie nouvelle. La thermodynamique est la science de base des systèmes complexes car elle est multidisciplinaire, comme l'est l'onde de détonation, ou physique et chimie coexistent. Nous pensons que le conseil de H.Poincaré faisant de cette science la base de la physique mathématique, est toujours d'actualité et reste toujours valable. Nous souhaitons que toute la partie non-linéaire de la physique et de la chimie ayant trait à la détonation utilise un peu plus la démarche thermodynamique qui me parait a l'heure actuelle quelque peu délaissée.

c) Le troisième point met l'accent sur le paramètre temps, si souvent difficile à maîtriser. Je 
renvoie encore au travail de pionnier de H.Poincaré dans l'étude des phénomènes instationnaires non-linéaires. Ce travail relance, sur de nouvelles bases, les réflexions concernant le déterminisme et la prédictibilité ; il joue un rôle essentiel dans la théorie moderne des systèmes dynamiques. La France a la chance de posséder d'excellents physiciens comme Bergé, Chabert, Pomeau, ... qui ont apporté beaucoup dans l'étude de la dynamique des systèmes. Paul Clavin est de ceux-là. Il peut faire progresser l'étude des phénomènes transitoires relatifs a la détonation.

Iwould like to thank Mrs Odiot for her kind invitation to chair this session. I believe much discussion is necessary in the complex field of detonation to explain and clarify our positions. I would like to stress three points I feel to be essential.

- The fundamental topic of the "Microscopic and Macroscopic Approaches to Detonation" workshop.

- The role of thermodynamics in the study of detonation.

- The importance of the time factor in analyzing these phenomena.

These three points are part of the modern development of nonlinear mechanics.

a) It is not possible to understand the coexistence of a shock wave and combustion wave without both a detailed local analysis performing in space $\left(10^{-7} \mathrm{~cm}\right)$ and time $\left(10^{-14} \mathrm{~s}\right)$, i.e. the "microscopic approach", and an anlysis of the overall repercussions, i.e. the "macroscopic approach". These two approaches are necessary and equally important. They cannot be dissociated, since they are complementary and interrelated. This is the approach adopted by Hadamard and Duhem. Poincaré insists on the importance of the transition from local to general, in particular in topology (analysis situs).

b) The second point stresses the importance of thermodynamics, in particular in analysis of the detonation. In the past, this role was crucial for determination of the velocity of detonation (importance of the production of entropy, which is a minimum downstream of the wave). We believe this role is still important, especially in the irreversible part which gives rise to a new theory. Thermodynamics is the basis science of complex systems, since it is multidisciplinary as is the detonation wave, in which physics and chemistry coexist. We feel that the recommendation of H.Poincaré, to make this science the basis of mathematical physics, is still valid today. We would like the thermodynamic approach, which appears somewhat neglected today, to be used more in the nonlinear part of the physics and chemistry of detonation.

c) The third point emphasizes the time parameter, often so difficult to control.I would again like to mention the pioneering work of H.Poincaré in the analysis of unsteady nonlinear phenomena. This work spurs new reflections on determinism and predictability on new bases. It plays an essential role in modern theory of dynamic systems. France is fortunate to have excellent physicists, such as Bergé, Chabert, Pomeau, who contributed enormously to research on system dynamics. Paul Clavin is another such physicist. He can help us progress in the study of transient phenomena relative to detonation. 


\section{LECTURES}

Direct Initiation of Gaseous Detonation ; P. Clavin and L. He

Analysis of Accelerating Detonation using Large Activation Energy Asymptoties.

R. Klein

Spontaneous Localization of Vibrational Energy ; D.w. Brown and L. Bernstein 